\title{
Impact of COVID-19 on Community Participation and Mobility in Young Adults with Autism Spectrum Disorders
}

\author{
Beth Pfeiffer ${ }^{1}$ - Eugene Brusilovskiy ${ }^{2} \cdot$ Taye Hallock $^{3} \cdot$ Mark Salzer $^{4} \cdot$ Amber Pompanio Davidson $^{3} \cdot$ Laura Slugg $^{3}$. \\ Cecilia Feeley ${ }^{5}$
}

Accepted: 26 April 2021 / Published online: 14 May 2021

(c) The Author(s), under exclusive licence to Springer Science+Business Media, LLC, part of Springer Nature 2021

\begin{abstract}
Transportation and mobility for community participation is difficult for persons with Autism Spectrum Disorders (ASD) under normal circumstances, but the impact of COVID-19 made access even more challenging. Researchers used a singlesubject design to examine patterns of change from before and after the COVID-19 pandemic in community mobility and participation as measured by GPS and daily participation questionnaires. Participants were young adults with ASD between the ages of 21 and 27 (4 males, 2 females) who were enrolled in a subsequent study. Community mobility and participation decreased for all participants in both essential and non-essential activities. Additionally, the number of trips for participants decreased substantially in the after COVID-19 periods, as did the variability in modes of transit.
\end{abstract}

Keywords Community mobility $\cdot$ Autism spectrum disorders $\cdot$ Participation $\cdot$ COVID-19 $\cdot$ GPS

\section{Introduction}

COVID-19 has created an unprecedented, rapidly changing environment that has significantly impacted daily life for everyone. On March 13, 2020 the United States declared a National Emergency in response to the novel coronavirus (Trump, 2020), and states responded by taking statelevel actions to restrict activities that put the population at increased risk of contracting the virus. Although restrictions

Beth Pfeiffer

bpfeiffe@temple.edu

1 Department of Health and Rehabilitation Sciences, College of Public Health, Temple University, 1913 North Broad Street, Suite 201H, Philadelphia, PA 19122, USA

2 Department of Social and Behavioral Sciences, College of Public Health, Temple University, 1700 N. Broad, Suite 313C, Philadelphia, PA 19122, USA

3 Department of Health and Rehabilitation Sciences, College of Public Health, Temple University, 1913 North Broad Street, Suite 201G, Philadelphia, PA 19122, USA

4 Department of Social and Behavioral Sciences, College of Public Health, Temple University, 1700 N. Broad, Suite 301, Philadelphia, PA 19122, USA

5 Rutgers Center for Advanced Infrastructure and Transportation, Rutgers University, 100 Brett Road \#118, Piscataway, NJ 08554, USA varied by state, they included school closures (Office of the Governor, 2020a, 2020b), shutdown of all "non-life sustaining businesses operations and services" (Wolf, 2020a), and stay home orders (Wolf, 2020b). Restrictions significantly disrupted, limited, or completely shut down participation in occupations related to leisure, work, education, and social participation. Even as many states progress through reopening phases, community participation patterns continue to fluctuate as a result of the evolving impact of COVID-19 and adjustment to the new normal of operating in the midst of a pandemic.

While COVID-19 has affected the entire population, people with Autism Spectrum Disorders (ASD) have been disproportionally impacted. Not only are people with developmental and behavioral disorders are at higher risk for becoming infected (Centers for Disease Control and Prevention, 2020a), many people with ASD have co-occurring medical conditions including obesity, cardiac and respiratory conditions (Jones et al., 2016; Kohane et al., 2012) that put them at increased risk of severe illness from COVID-19 (CDC, 2020b). People with ASD also experience the social and mental health consequences of COVID-19 restrictions on community participation more acutely than the general population. Much of the general population has experienced the impact of disrupted routines, reduced social interaction, and physical activity on 
their health and well-being (Galea et al., 2020; Serafini et al., 2020), including increases in anxiety and depression, substance use, loneliness, and domestic violence (Galea et al., 2020). But for people with ASD, who already face a number of barriers to community and social participation (Emerson \& Hatton, 2008; Liptak et al., 2011; Myers et al., 2015; Simpson et al., 2019), COVID-19 restrictions compound these barriers to exacerbate social and mental health consequences. For example, lockdowns and social distancing significantly disrupts daily routines, increasing stress and isolation (Courtenay \& Perera, 2020; Jeste et al., 2020; Manning et al., 2020; Patel et al., 2020; Pellicano \& Stears, 2020).

Community mobility is one domain of participation where COVID-19 restrictions have significantly impacted people with ASD. Community mobility is defined as "moving around in the community and using public or private transportation, such as driving, walking, bicycling, or accessing and riding in buses, taxi cabs, or other transportation systems" (American Occupational Therapy Association [AOTA], 2008). Transportation affects people's access to employment, housing, social, educational, and recreational opportunities, thus contributing to a person's health and quality of life by promoting independence and enabling participation (AOTA, 2008; Feeley et al., 2015; Friedman \& Rizzolo, 2016; Newman et al., 2011). People with ASD experience less independent use of public transportation and consistent barriers to community mobility (Davies et al., 2010; Haveman et al., 2013; Pfeiffer et al., 2018, 2020; Price et al., 2018), and these barriers have increased as COVID-19 has triggered disruptions in service and significant changes to public transportation systems, such as new policies and procedures (Federal Emergency Management Agency, 2020; Metropolitan Transportation Authority, 2021; Southeastern Pennsylvania Transportation Authority, n.d.). While mass transit has largely resumed regular operations in major cities, there continue to be masking rules, capacity limits, and social distancing guidelines (Groover, 2020; Guse, 2020; Hawkins, 2020). These new guidelines, combined with a significant reduction of in-person employment, therapeutic and healthcare services due to provider and agency closures and the subsequent shift to remote learning and telehealth (Jeste et al., 2020; Manning et al., 2020), limit means for travel and reasons to travel or possible destinations. As a result, people with ASD miss out on occasions for independent travel to facilitate social, recreational, leisure related participation and associated skill development, and generally experience even fewer opportunities for community participation. It is important to understand the impact that COVID-19 restrictions have on participation patterns for people with ASD and their subsequent influence on well-being. This will foster the development of supports, services and policies that minimize the impact of social isolation, secondary mental health disorders, and the many negative effects of restrictions that result in reduced community participation.

There are a number of innovative techniques to measure community mobility and participation. In addition to traditional self-report measures, Global Positioning Systems (GPS) is a more recent technique and technology that has been used across a broad range of participants, with and without disabilities, to measure community mobility (Brusilovskiy et al., 2016). It has the ability to measure a variety of mobility-related constructs including destinations (i.e., number of trips; number of unique destinations; total number of locations), geographic scope (i.e., distance traveled; activity space), and temporal scope (i.e., time spent in the community; time spend in transit) (Boissy et al., 2018; Brusilovskiy et al., 2016; Chan et al., 2020). GPS technology was used to identify mobility trends related to COVID-19 recommendations and restrictions with the general population (Kishore et al., 2020; Kraemer et al., 2020; Lee et al., 2020), although there is very limited research using GPS with individuals with ASD. Much of the available research focuses on children with ASD and social communication in community settings (Little et al., 2019; Little \& Irvin, 2018) with GPS used to determine location in community and communication identified as the primary outcome. In one study by Fazana et al. (2017), the limitations and benefits of using wearable technologies, including GPS, to monitor communication skills and health outcomes for children with ASD are identified. This research did not examine specific impacts on community mobility nor did it focus on adults with ASD.

Therefore, the purpose of this study is to apply GPS methods and daily participant questionnaires to measure changes in activity space use and to examine the impact of COVID19 on community mobility and participation in a group of people with ASD. Specific research questions included:

(1) Are there differences in mobility for transitional age youth and young adults with ASD before and after the COVID-19 pandemic?

(2) Are there changes in the number and types of activities in the community for transitional age youth and young adults with ASD before and after the COVID-19 pandemic?

(3) Are there changes in the number and types of transportation modes used by transitional age youth and young adults with ASD before and after the COVID-19 pandemic?

\section{Methods}

\section{Design}

Researchers used a single-subject design to examine patterns of change over time in community mobility as measured 
by GPS. Additionally, changes in transportation modes and participation activities were measured by daily surveys. Participants were enrolled in another study which collected location data with GPS-enabled cell phones, described later, allowing researchers to have access to both before COVID19 and after COVID-19 community mobility data. Participants also completed daily activity and transportation logs on the cell phones through Qualtrics. Data was available for two weeks before COVID-19 and collected immediately after COVID-19 restrictions were implemented statewide over 2 two week periods of time.

\section{Participants}

Six transitional age youth and young adults with ASD between the ages of 21 to 27 (4 males, 2 females) participated in the study. Participants were recruited from community organizations that provide services and supports for transitional age youth and young adults with ASD. All participants were part of another study that required confirmation of an ASD diagnosis through medical or school documentation, as well as a score of 65 on the Ritvo Autism Asperger Diagnostic Scale - Revised (RAADS-R). A score of 65 on the RAADS-R is the cut score that indicates an Autism diagnosis is very probable. Participants completed a Transportation Pre-Screening Assessment for inclusion in the other study that identified that they were safe to learn to travel on public transportation. This suggests that they can travel in their community either independently or with distant supervision.

\section{Procedures}

IRB approval was obtained from the first author's university affiliation for this study. Participants engaged in the consent process through the use of Zoom video conferencing technology and were provided consent documentation through email. Once consent information was reviewed online, participants signed the consent form and returned it via e-mail. All participants were enrolled in another study in which they were provided with GPS-enabled mobile phones to collect location data, described below. Additionally, participant report data was collected daily for types of community participation activities and modes of transportation used through a Qualtrics online survey. GPS and participant report data were collected for two weeks before the initial COVID-19 shutdowns (between January 3rd and February 29th, 2020), and at one or two additional two-week tracking periods after COVID-19 statewide restrictions and shutdowns were instituted in the state of Pennsylvania. Specifically, the second tracking period was at the very beginning of the COVID-19 lockdown (between March 20th and April 2nd), and the third tracking period started a month later (between April 20th and May 3rd). One of the participants only had two tracking periods (before COVID-19 and the tracking period between April 20th and May 3rd). Having several tracking periods for each participant provided access to both before COVID-19 and after COVID-19 data.

\section{Measures}

\section{Daily Transportation and Participation Questions}

Participants completed daily transportation and participation questions (see Table 1) through an online Qualtrics survey to identify community-based activities and the modes of transportation to get to these activities each day. A question about the general location of the activity was also included to provide information to validate GPS data. The link to the Qualtrics survey questions was sent to participants on the provided cell phones at a time at the end of the day that was deemed most convenient by each person.

Data collected from the daily transportation and participation questions were coded into types of daily activities categories. The categories included social activities (SA); recreational, leisure, and/or exercise activities (RLEA); activities of daily living (ADLs) and instrumental activities of daily living (IADLs); employment, volunteer and/or educational activities (EVEA); and medical, social services and/or therapeutic activities (MSSTA). Daily activities were also categorized into essential versus non-essential activities based on guidelines provided by the Pennsylvania Department of Health. Essential activities include attending work or school or activities to meet essential needs such as seeking medical care, providing childcare or eldercare, going to the grocery store or pharmacy, picking up food or exercising (Office of the Governor, 2020a, 2020b). In contrast, nonessential activities included social gatherings, indoor dining, beauty and personal care services, entertainment, and recreational and tourist activities. Transportation modes were categorized into driving a personal vehicle, passenger in a car, public transportation, biking, taxi/Uber/Lyft, walking and the use of mixed modes. Initial coding was completed by one researcher but validated by multiple researchers on the team. Consensus was obtained by a minimum of three different researchers for the codes and categories for each participant. Daily frequencies were used for data analysis for the types of daily activities, essential versus non-essential activities, and modes of transportation.

\section{GPS Data}

AccuTracking (www.accutracking.com) software was used for tracking the locations and movement of study participants for each of the three two-week periods. AccuTracking software has been used in several published studies 
Table 1 Daily participation and transportation questions

How many trips did you take into the community today?

Where did you go and how did you get there?

Type of community-based activity/activities: (select all that apply)

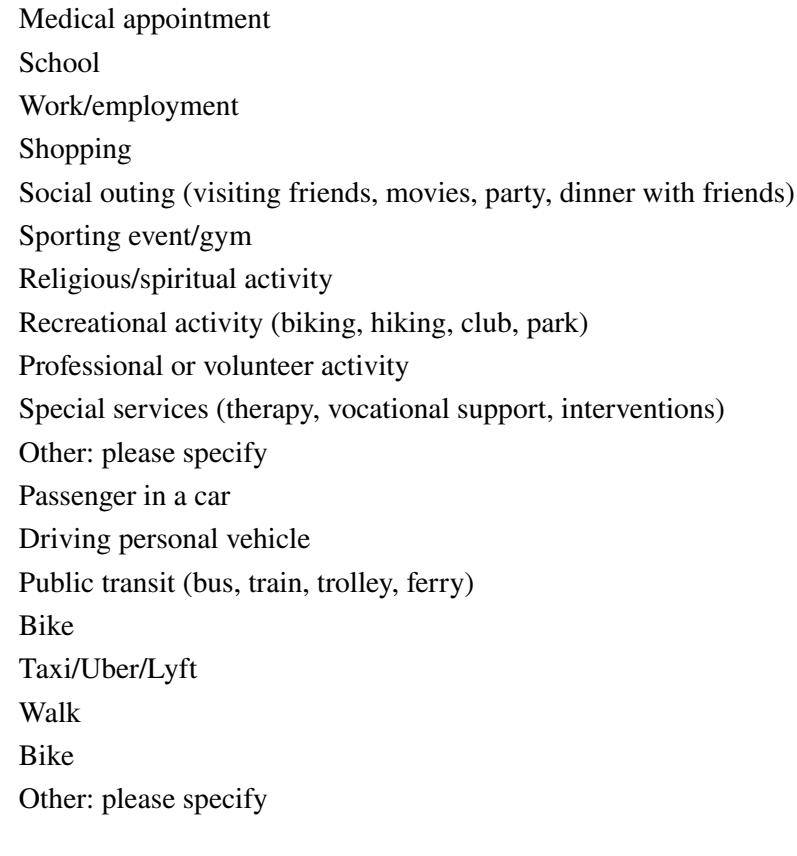

What was the general location of the activity/activities?

(Brusilovskiy et al., 2016, 2020; Zhou et al., , 2004, 2005). Compatible with most modern Android cellular phones, the software tracks latitude and longitude of the phone at one-minute intervals. Whenever cellular coverage is available, real time location data are transferred to the secure AccuTracking online database; otherwise, location data are cached on the phone and transferred at a later time. As each tracking period location was recorded every minute for 14 full days, the total number of points that could be obtained was $1 \mathrm{record} / \mathrm{min} \times 1440 \mathrm{~min}$ in a $24 \mathrm{~h}$ period $\times 1424$-h periods $=20,160$ records.

Due to satellite, receiver, multipath and other errors that might occur with data collection, GPS tracking often results in a substantial amount of missing data, and thorough data cleaning, including deduplication, removal of outliers, and linear interpolation, is necessary prior to creating the relevant constructs. These steps are described in detail in prior peer reviewed publications by research team members (Brusilovskiy et al., 2016, 2020). All participants had at least $75 \%$ of the data $(15,120 \mathrm{~min})$ at each tracking period after data cleaning and imputation. This was greater than the $50 \%$ threshold for inclusion in data analyses used in other studies (Brusilovskiy et al., 2016, 2020). This included five participants with data for all three tracking periods, and one participant with data for the initial and final tracking periods.

A spatio-temporal data mining algorithm, ST-DBSCAN (Birant \& Kut, 2007) was employed to identify destinations from GPS data using a custom $\mathrm{R}$ program (Brusilovskiy et al., 2020). The algorithm has three parameters, called eps 1 (spatial distance), eps 2 (temporal distance) and minpts (minimum number of points necessary to form a cluster. Consistent with earlier studies (Brusilovskiy et al., 2016, 2020; McCormick et al., 2021), we set the values of these parameters to $200 \mathrm{~m}, 20 \mathrm{~min}$, and 10 points, respectively. Roughly speaking, this means that the individual is in a cluster, or at a destination, when there are at least 10 points which are within $200 \mathrm{~m}$ and $20 \mathrm{~min}$ of each other. Outlier points which don't fall into a cluster are considered to be transit points. An additional algorithm, described by Brusilovskiy et al. (Brusilovskiy et al., 2016) that is used to modify clusters identified by ST-DBSCAN and create new ones in the presence of missing data, is also implemented in this study.

In addition to identifying the total number of destinations, we also calculated the number of non-home destinations, defined as destinations with centroids more than $200 \mathrm{~m}$ away from the individual's geocoded home address. Furthermore, since participants could visit some destinations more than once over the course of each tracking period, we calculated the number of unique destinations, as described in Brusilovskiy et al. (Brusilovskiy et al., 2020). In addition, we computed the amount of time each individuals spent outside of home - i.e., at non-home destinations and in transit. Lastly, we calculated the total distance the individual traveled over the course of each tracking period, as well as 
the median daily activity space area. The activity space was generated as the minimum convex polygon around all of the individual's GPS points for a specific day. All of these variables were computed for each of the three tracking periods; however, the activity space area was also computed for each day of tracking which had at least $12 \mathrm{~h}$ or more worth of data (i.e., at least half of the data points) after imputation.

\section{Analysis}

Data was analyzed using common single-subject methodology through visual analysis. Overall and daily data in each tracking period were examined for each participant. Due to a small sample size $(\mathrm{N}=6)$, statistical analyses were not completed.

\section{Results}

\section{Demographics}

Four participants were male and two were female. Four were white, one was black, and one was Native American. The average age was 23.5 years (SD 2.4; range 21-27). Five of the participants had at most a high school education, and one went on to receive post-high school education. Two lived in Philadelphia, and four lived in the Philadelphia suburbs. All participants lived with their parents. Four had a DSMIV diagnosis of Autistic Disorder, one had a diagnosis of Asperger's Disorder, and one did not know their specific Autism diagnosis. Four of the six participants received home and community-based services focused on supporting active engagement and independence in community settings through a daily program. These services were either suspended or provided in virtual formats during COVID-19 restrictions. Another participant reported receiving peer supports services and the final participant reported receiving no supportive services.

Prior to COVID-19 statewide restrictions, five of the six participants identified as having part-time employment, whereas one participant identified that they were not employed. During COVID-19 restrictions, four out of the six identified as having part-time employment in essential types of jobs including cleaning/custodian $(n=3)$ and meal preparation/packaging $(n=1)$. It is important to note that the one unemployed participant obtained work during this time, whereas two other participants changed their work status from part-time employment to not employed. Prior to COVID-19, three people got to work by being driven by a family member or another person, one used public transportation and one walked to work. After COVID-19 restrictions, all participants reported being driven to work by a family member or another person.

\section{Overall Community Mobility}

Figure 1 shows the number of essential and non-essential activities the participants were involved in at each of the three tracking periods. Although the total number of activities was lower in the after COVID-19 tracking periods for each participant, some participants $(1,5,6)$ engaged only in essential activities, and some participants $(2,3,4)$ engaged only or mostly in non-essential activities at the follow up times. Similarly, Fig. 2 shows that the number of trips for participants decreased substantially in the after COVID-19 periods, as did the variability in mode of transit. Furthermore, although some participants took public transportation and taxi, Uber of Lyft in the before COVID-19 period, the only two modes of transit in the after COVID-19 period were walking and being driven.

Table 2 shows all of the GPS constructs calculated for the participants at each tracking period. Although the two after COVID-19 periods do not seem to be markedly different for most of the participants on any of the community mobility variables, community mobility seems to be substantially lower than it was prior to COVID-19. This can be visualized in Fig. 3, which shows standardized GPS variables for the 3 tracking periods for each participant.

\section{Daily Community Mobility and Participation}

In addition to presenting each participant's aggregated data on community mobility, essential activities and transportation utilization for each tracking period, we also present charts demonstrating daily activity space area and activities in Figs. 4, 5, 6, 7, 8 and 9. The horizontal axis in these charts shows the day of tracking, day of the week, and the study period; the vertical axis on the left shows the activity space area in $\mathrm{km}^{2}$; and the vertical axis on the right shows the number of different activities that the individual was engaged in on each day. The chart for each participant shows substantial variability in daily activity space area and the number and type of activities in the before COVID-19 tracking period. However, both the activity space area and the number of activities are markedly lower in the two after COVID-19 tracking periods.

Figure 4 shows that on about half of the days in the before COVID-19 tracking period, the first participant engaged in one or two RLEA, and on several days, the individual participated in ADL/IADL, MSSTA, and EVEA. At the two after COVID-19 tracking periods, daily activity space area was close to $0 \mathrm{~km}^{2}$ except on most Saturdays, on which the individual participated in an ADL/IADL. The individual 


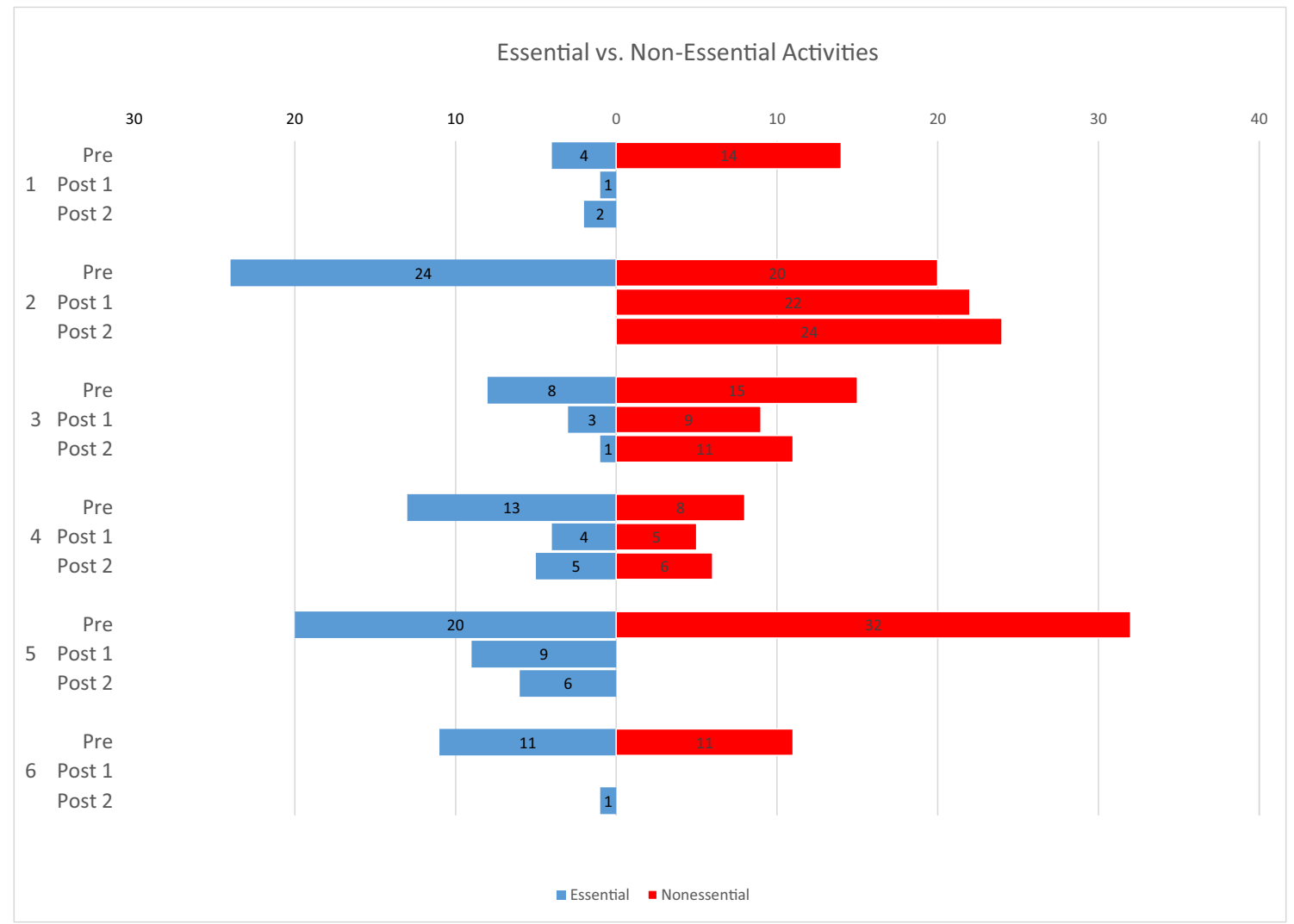

Fig. 1 Essential vs. non-essential activities

reported no other types of activities on any of the days in either after COVID-19 tracking period.

With the exception of ADL/IADL, in which the second participant engaged only on one of the days, the individual had multiple days with participation in SA, EVEA, RLEA and MSSTA in the before COVID-19 period, as shown in Fig. 5. The activity space area seemed to be lower on weekends, although lower activity space area did not always correspond to fewer activities, many of which could be happening close to home. In the two after COVID-19 time periods, the participant engaged in two RLEA on most weekdays and at most one RLEA on weekend days. Furthermore, the participant engaged in one SA over the course of each after COVID-19 tracking period. The daily activity space area remained close to 0 on all days.

On the first two days of the initial after COVID-19 tracking period, the third participant (Fig. 6) had very large activity space areas of over $2500 \mathrm{~km}^{2}$; on those days, she traveled out of state making some stops along the way. After this trip, the participant's activity space area was substantially lower, and she only engaged in RLEA and ADL/IADL during both after COVID-19 tracking periods, without engaging in any SA, MSSTA or EVEA as she had during the before COVID-19 period.
The fourth participant (Fig. 7) participated in EVEA on about half of the days in the before COVID-19 tracking period, however he was no longer engaged in these activities in the two after COVID-19 periods. On most days in the after COVID-19 tracking periods, the activity space area was lower than in the before COVID-19 period, and the individual engaged only in RLEA, ADL/IADL and one SA.

The fifth participant (Fig. 8) participated in a variety of activities, had multiple destinations and large activity spaces on several the days in the before COVID-19 period. However, as with other participants, the activity space area decreased substantially in the two after COVID-19 tracking periods, and her activities were limited to just ADL/ IADL.

During the before COVID-19 tracking period, the sixth participant made several trips, including one out of state trip and as shown in Fig. 9, to participate in numerous activities. The participant only had one after COVID-19 period, during which the activity space area was very low on most days, with the exception of one Saturday, on which the individual participated in an EVEA. 


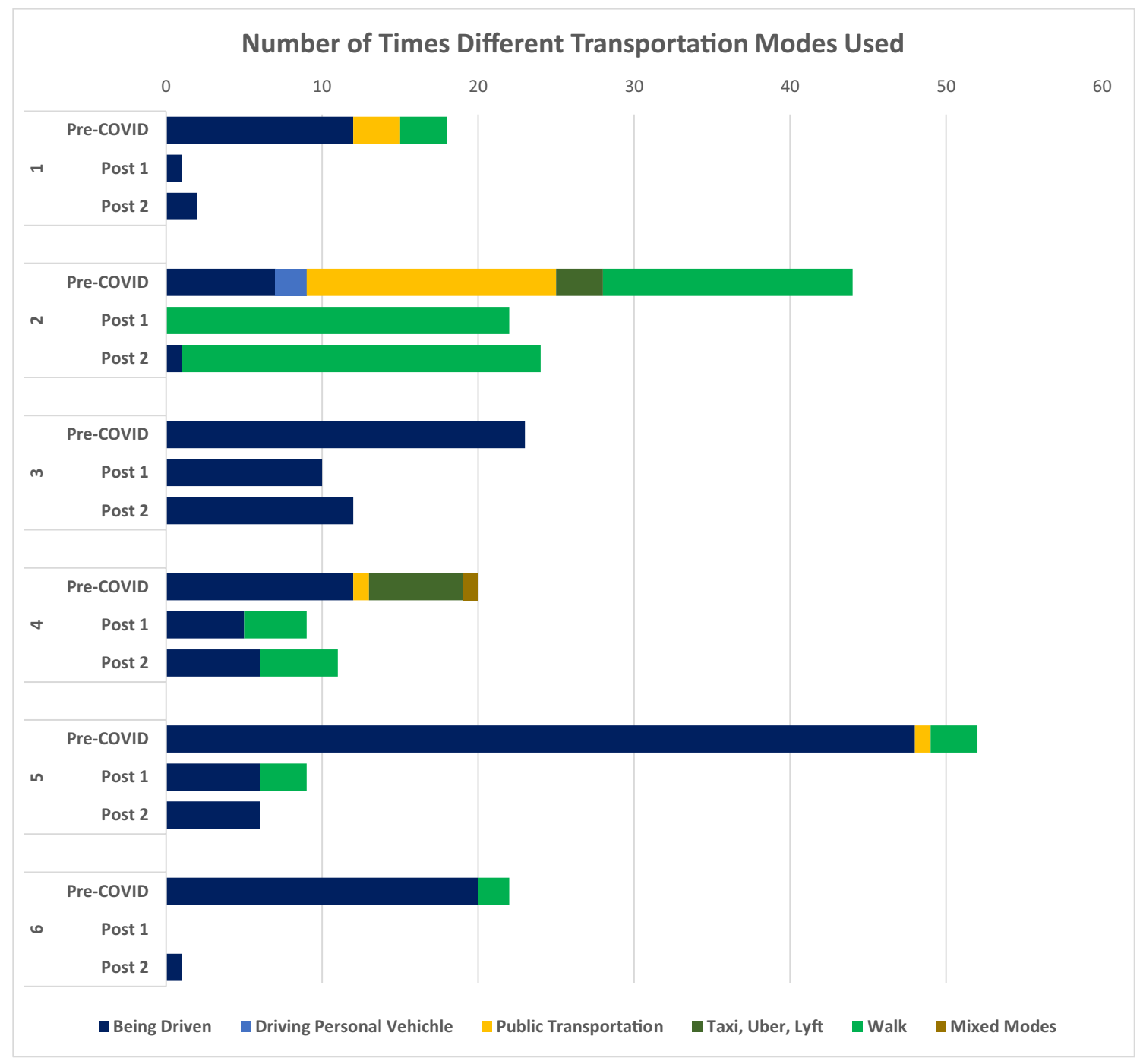

Fig. 2 Self-reported number of trips and transportation modes

\section{Discussion}

Transportation and mobility for community integration is difficult for persons with ASD under normal circumstances (AOTA, 2008; Feeley et al., 2015; Friedman \& Rizzolo, 2016; Newman et al., 2011), but the impact of COVID-19 made access even more difficult. COVID-19 had a significant impact on the lives of the six study participants based on GPS and daily reporting data. For all participants, the number of trip destinations, as well as travel modes, were substantially reduced during the first after COVID-19 period which immediately followed the closure, with only very small increases in the second after COVID-19 period. Specifically, all six of the study participants had significant reductions in the after COVID-19 periods in transportation modes used, total destinations for all five categories analyzed, time out of home, median daily activity living space, and distance traveled. Business closures and shutdowns significantly decreased activities by restricting services to those deemed essential (Office of the Governor, 2020a, 2020b; Wolf, 2020a). All participants had reduced trips for essential function. Additionally, five of the six participants had reduced trips for non-essential functions, with two making zero trips for non-essential functions.

These findings are consistent with research conducted with the general population that identified an overall reduction in community mobility. As identified previously, community mobility involves moving around in the community through public or private transportation modes (AOTA, 2008). In a study by Lasry et al. (2020), there was a substantial decrease in community mobility in four major cities in the United States between late February and early April that corresponded to increases in case counts and public policies related to social distancing. In another study (Borgonovi \& 
Table 2 GPS constructs for the 6 participants for the 3 tracking periods

\begin{tabular}{|c|c|c|c|c|c|c|c|c|c|}
\hline Participant & Tracking period & $\begin{array}{l}\text { \# Miss- } \\
\text { ing } \\
\text { Minutes }\end{array}$ & $\begin{array}{l}\% \text { missing } \\
\text { minutes (out of } \\
20,160 \text { ) }\end{array}$ & $\begin{array}{l}\text { Total } \\
\text { destina- } \\
\text { tions }\end{array}$ & $\begin{array}{l}\text { Non-home } \\
\text { destina- } \\
\text { tions }\end{array}$ & $\begin{array}{l}\text { Unique } \\
\text { destina- } \\
\text { tions }\end{array}$ & $\begin{array}{l}\text { Time out of } \\
\text { home (min- } \\
\text { utes) }\end{array}$ & $\begin{array}{l}\text { Distance } \\
\text { traveled } \\
(\mathrm{km})\end{array}$ & $\begin{array}{l}\text { Median daily } \\
\text { activity space area } \\
\left(\mathrm{km}^{2}\right)\end{array}$ \\
\hline 1 & Pre-COVID & 2625 & $13.02 \%$ & 63 & 33 & 16 & 3161 & 493.78 & 27.42 \\
\hline 1 & $\begin{array}{l}\text { Post } 1: 3 / 20 / 20- \\
4 / 2 / 20\end{array}$ & 3654 & $18.13 \%$ & 19 & 0 & 1 & 55 & 65.42 & 0.00 \\
\hline 1 & $\begin{array}{l}\text { Post 2: 4/20/20- } \\
5 / 3 / 20\end{array}$ & 302 & $1.50 \%$ & 12 & 5 & 5 & 301 & 136.30 & 0.00 \\
\hline 2 & Pre-COVID & 1280 & $6.35 \%$ & 75 & 63 & 26 & 4913 & 430.67 & 17.87 \\
\hline 2 & $\begin{array}{l}\text { Post } 1: 3 / 20 / 20- \\
4 / 2 / 20\end{array}$ & 0 & $0.00 \%$ & 37 & 20 & 3 & 703 & 13.16 & 0.16 \\
\hline 2 & $\begin{array}{l}\text { Post 2: 4/20/20- } \\
5 / 3 / 20\end{array}$ & 1 & $0.00 \%$ & 60 & 36 & 2 & 958 & 17.52 & 0.18 \\
\hline 3 & Pre-COVID & 2188 & $10.85 \%$ & 84 & 58 & 25 & 4579 & 643.78 & 39.35 \\
\hline 3 & $\begin{array}{l}\text { Post } 1: 3 / 20 / 20- \\
4 / 2 / 20\end{array}$ & 3601 & $17.86 \%$ & 43 & 15 & 8 & 1976 & 457.21 & 1.00 \\
\hline 3 & $\begin{array}{l}\text { Post 2: 4/20/20- } \\
5 / 3 / 20\end{array}$ & 1744 & $8.65 \%$ & 59 & 32 & 4 & 778 & 64.43 & 0.99 \\
\hline 4 & Pre-COVID & 4803 & $23.82 \%$ & 45 & 25 & 19 & 1936 & 354.09 & 7.18 \\
\hline 4 & $\begin{array}{l}\text { Post } 1: 3 / 20 / 20- \\
4 / 2 / 20\end{array}$ & 3632 & $18.02 \%$ & 27 & 2 & 3 & 119 & 38.31 & 0.01 \\
\hline 4 & $\begin{array}{l}\text { Post } 2: 4 / 20 / 20- \\
5 / 3 / 20\end{array}$ & 3668 & $18.19 \%$ & 33 & 4 & 5 & 253 & 86.26 & 0.01 \\
\hline 5 & Pre-COVID & 2282 & $11.32 \%$ & 91 & 54 & 18 & 4657 & 560.19 & 15.52 \\
\hline 5 & $\begin{array}{l}\text { Post } 1: 3 / 20 / 20- \\
4 / 2 / 20\end{array}$ & 1739 & $8.63 \%$ & 22 & 2 & 3 & 171 & 50.54 & 0.02 \\
\hline 5 & $\begin{array}{l}\text { Post 2: 4/20/20- } \\
5 / 3 / 20\end{array}$ & 4407 & $21.86 \%$ & 27 & 2 & 3 & 174 & 101.70 & 0.56 \\
\hline 6 & Pre-COVID & 1955 & $9.70 \%$ & 74 & 34 & 20 & 5514 & 1287.73 & 30.69 \\
\hline 6 & $\begin{array}{l}\text { Post } 2: 4 / 20 / 20- \\
5 / 3 / 20\end{array}$ & 2383 & $11.82 \%$ & 31 & 0 & 1 & 39 & 30.87 & 0.01 \\
\hline
\end{tabular}

Andrieu, 2020), community mobility decreases were associated with high case counts and higher social capital in the general population. Non-essential retail and recreation activities decreased more substantially in those communities that had greater social capital.

The current study also identified changes in transportation modes from before and after COVID-19 time periods. During the before COVID-19 period, five of the six participants traveled by at least two modes, with one traveling by five different modes. However, in both of the after COVID-19 periods, the modes were limited to being driven and/or walking. The reductions to mode choices mirrored that of the general public, which reflected substantial reductions in the use of public transit and ridehailing services (Thompson \& Nygren, 2020). Consistent with other research (Cochran, 2020; Thompson \& Nygren, 2020), this study revealed the most significant decline was in the use of public transit. In the before COVID-19 study period, four participants used public transit, ranging from once to 16 times during the 2 week study period. In the after COVID-19 period, none of the participants used public transit. Two participants utilized ride-hailing services in the before COVID-19 period, yet none used the services at all during either of the after COVID-19 periods. The one participant who drove themselves before COVID-19 did not drive at all during either of the after COVID-19 periods.

Perhaps the most significant contribution of this study is to illustrate the lack of access to different transportation modes during the after COVID-19 periods. None of the six participants reported any type of travel provided by a social or human services agency to ensure essential needs were being met during this time period. As described in the Daily Community Mobility and Participation questionnaires, the first participant only traveled three times during the two after COVID-19 periods and only for ADLs/IADLs. This was even more significant for the second participant who used five different modes for community mobility during the before COVID-19 period, but only walked for nonessential purposes including RLEA and a few SA. Participant 2 only traveled once during this timeframe and was driven by someone else for an essential purpose. 


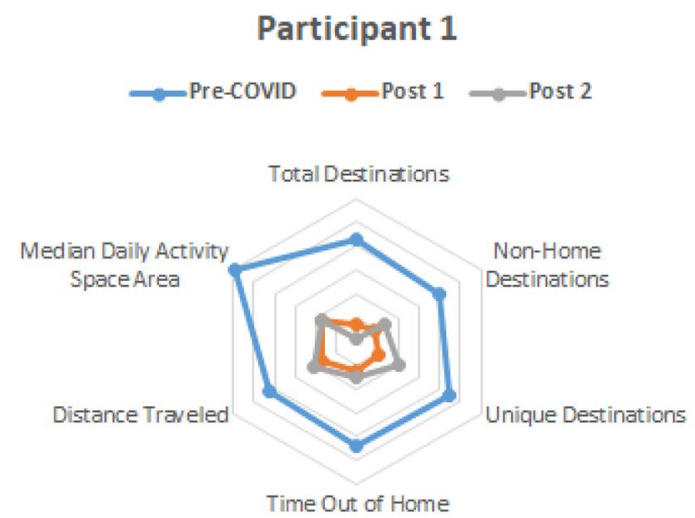

Participant 3

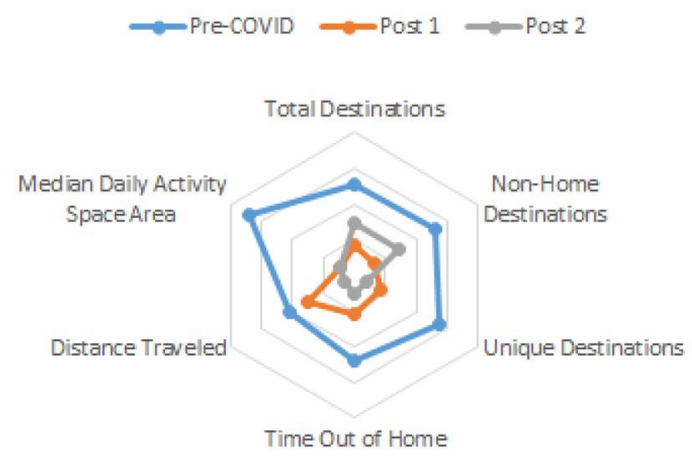

Participant 5

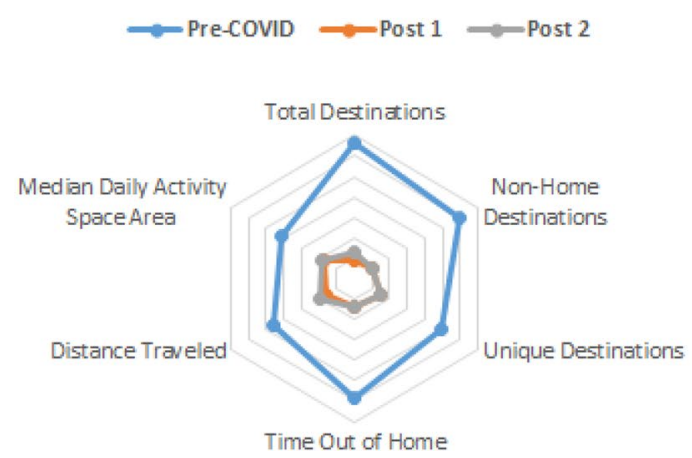

Fig. 3 GPS constructs for the 6 participants for the 3 tracking periods

While research on the impacts on people with disabilities, and specifically those with autism, are still emerging, the results of this study reflect the findings of other research that has been published since COVID-19 significantly impacted daily life. A recent study by Cochran (2020) found that people with disabilities had issues with using public transportation during the early months, as well as difficulties getting up-to-date information on the availability and requirements for using public transit services and/or obtaining transportation services necessary for daily living. Thompson and Nygren (2020) identified
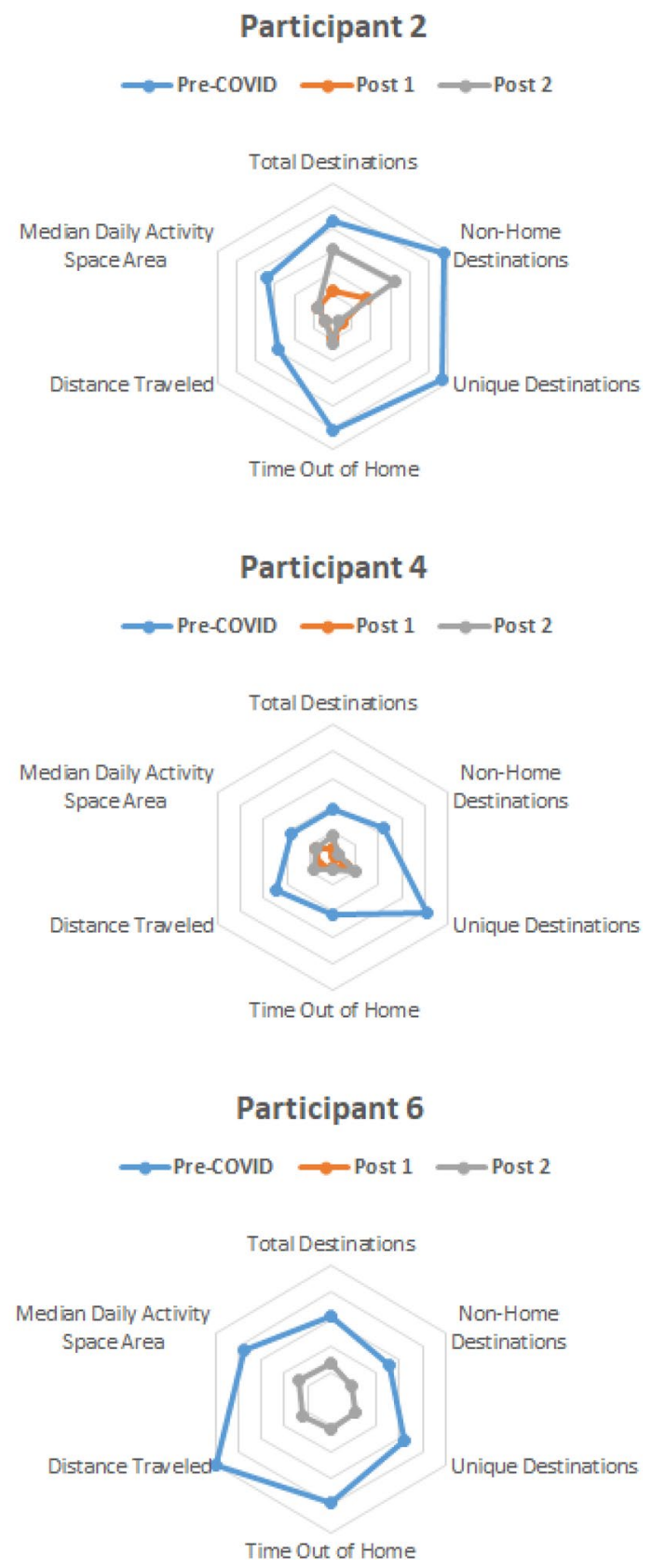

the negative impacts on individuals with developmental disabilities from changes in public transportation related to the COVID-19 pandemic including lack of dependability, limited schedules and costs. Constantino et al. (2020) identified that barriers to transportation still prevented access to necessary medical care and other activities of daily living, even with subsequent shifts to telehealth and remote learning (Jeste et al., 2020; Manning et al., 2020). The Office of Civil Rights at the Department of Health and Human Services (HHS) recognized that people with disabilities lacked accessible transportation resulting in a 


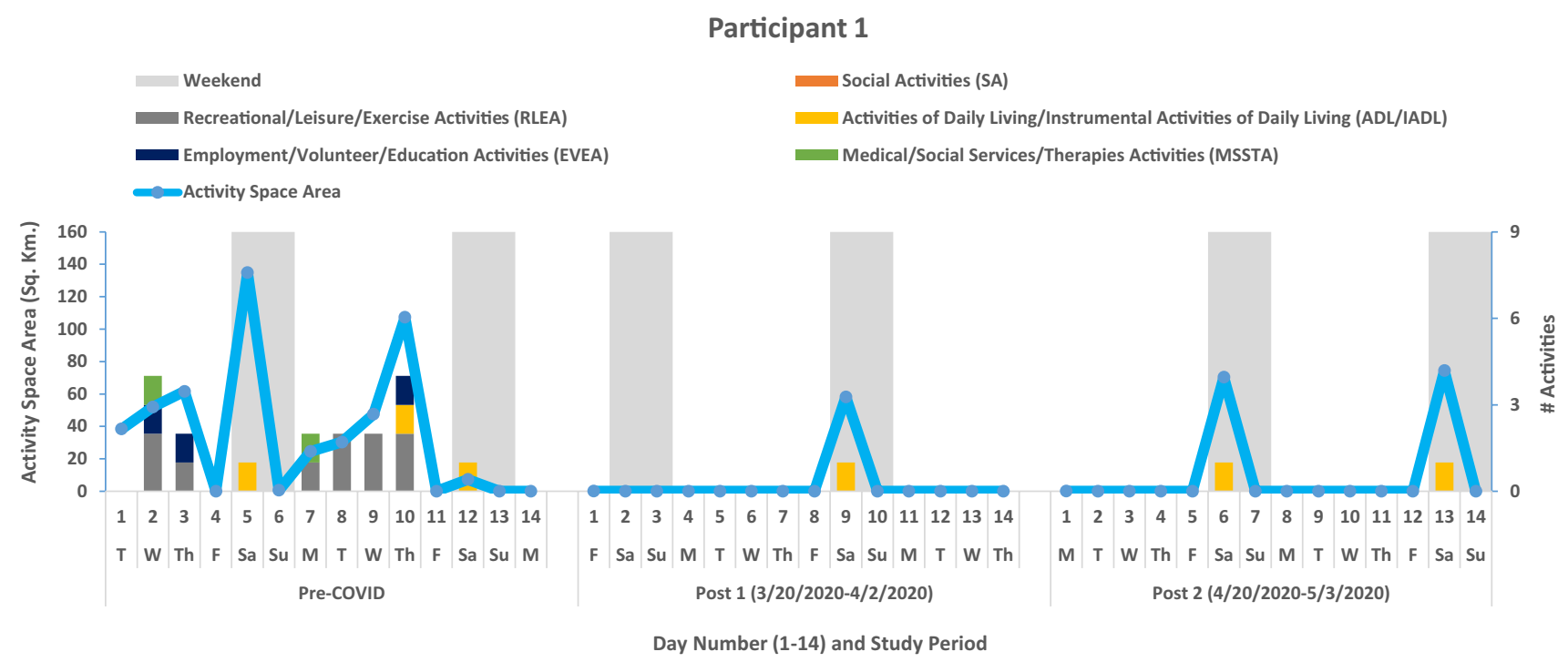

Fig. 4 Daily activity space area, destinations and activities for participant 1

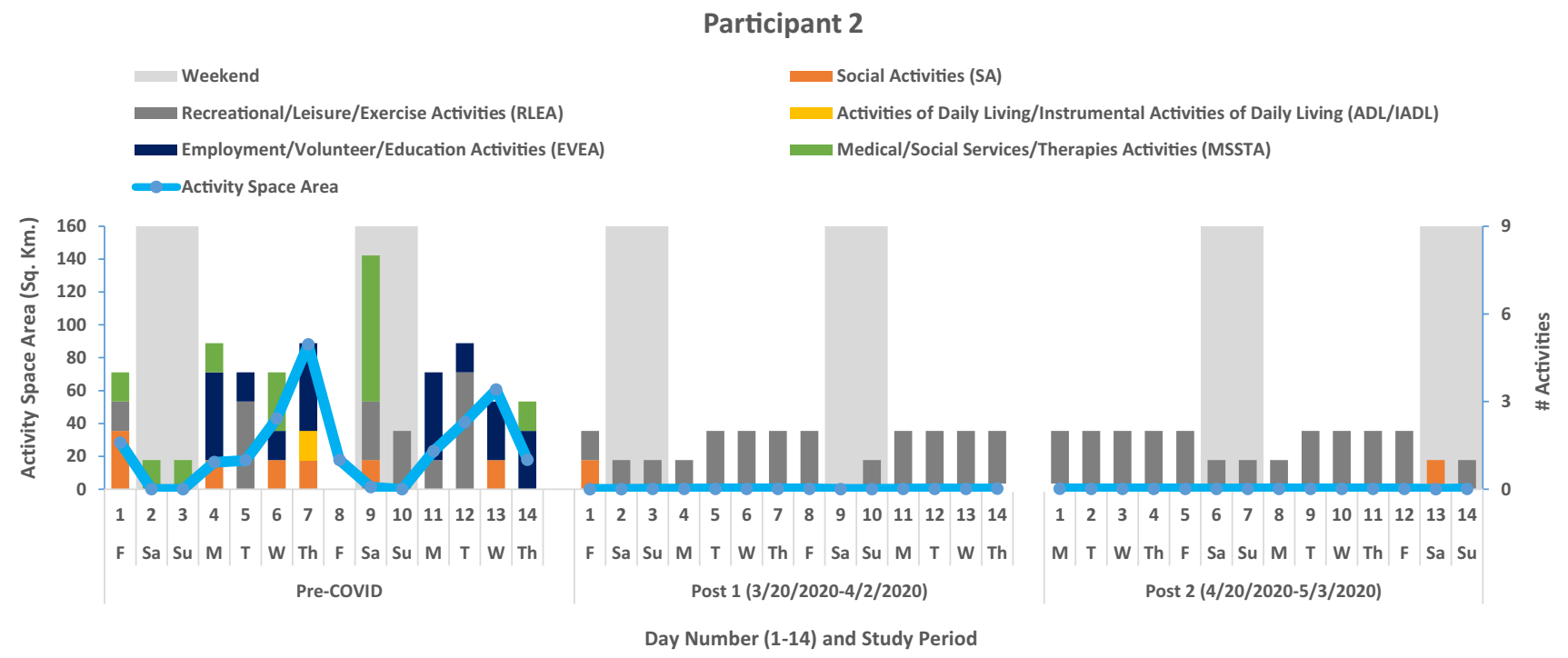

Fig. 5 Daily activity space area, destinations and activities for participant 2

negative impact on those requiring medical care during the COVID-19 crisis (Solomon et al., 2020).

\section{Limitations and Future Research}

There were limitations of the study that related to retrospective data collection process and the focus on mobility for participation in the physical community. Data collection methods did not account for participation in non-community settings (e.g., home) that were completed through remote technologies and telehealth. Many people shifted locations (e.g., home) and methods (e.g., over the computer or gaming device) of community participation, but continued engagement in social and recreation activities, as well as certain IADLs. The daily activities logs and GPS technology used to collect this data did not reveal if any essential or non-essential needs were met remotely or identify the specific unmet needs of participants during the study period. Additionally, the single subject design of the study provides important information about the unique experiences of subset of young adults with ASD with a level of function that allowed them to participate in the community either independently or with distant supervision. This may not represent the range of experience across the autism spectrum for those that need more support for community participation. 


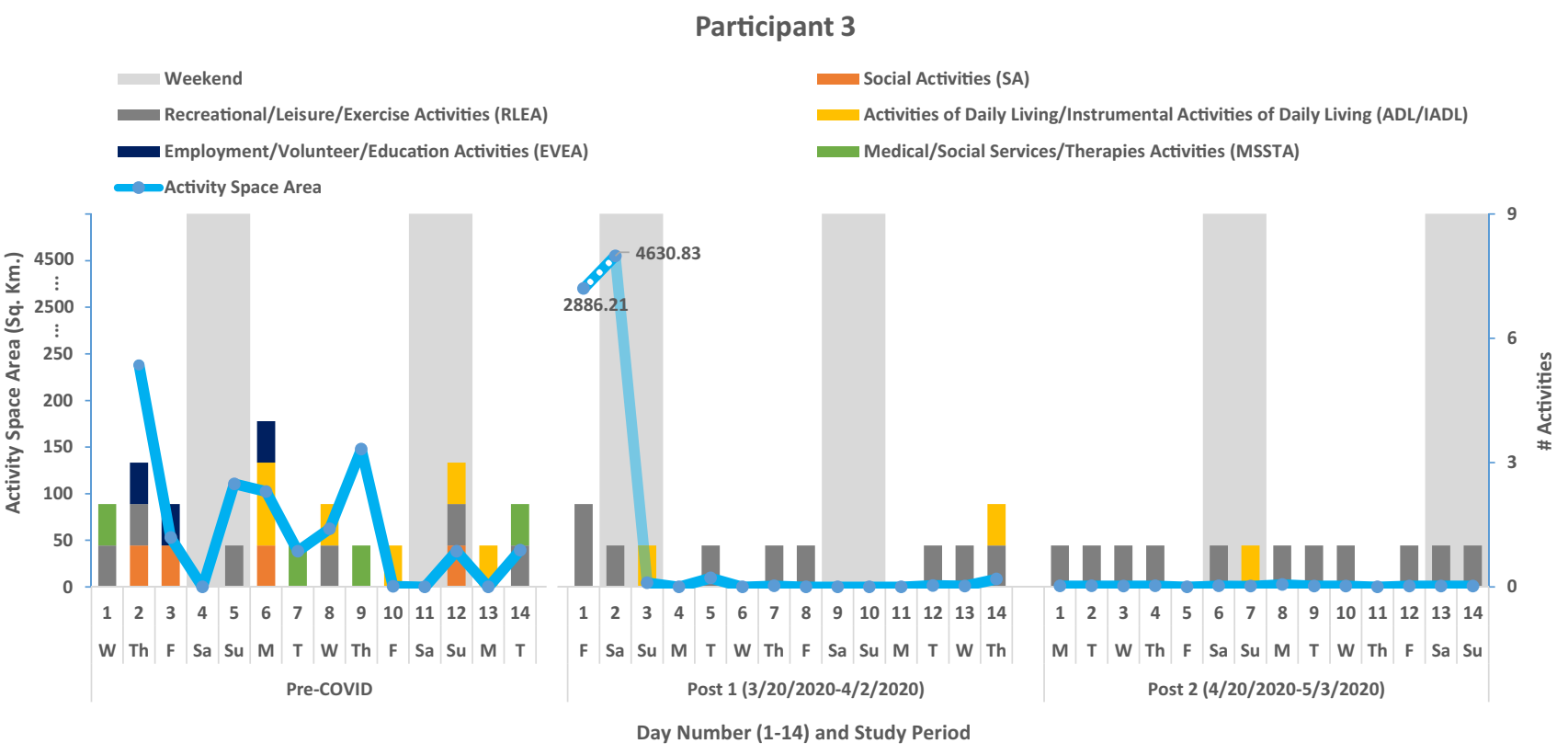

Fig. 6 Daily activity space area, destinations and activities for participant 3

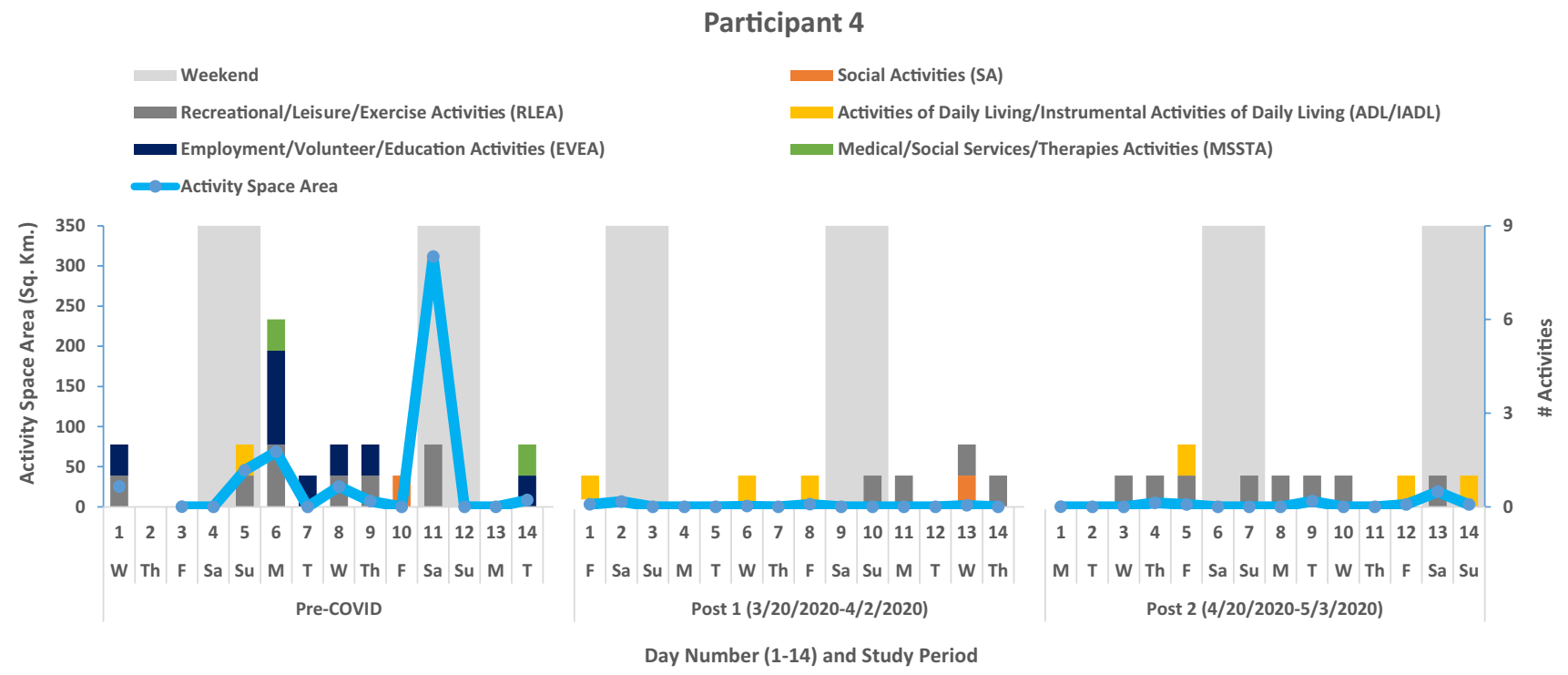

Fig. 7 Daily activity space area, destinations and activities for participant 4

There are a number of recommendations for future research involving the impacts of COVID-19 on persons with the ASD. These findings illustrated that all 6 participants partook in some type of EVEA activity in the before COVID-19 period, but only one participant traveled for EVEA during the second after COVID-19 period. It is important to expand data collection methods to consider if EVEA activity was able to continue remotely or was discontinued, and if discontinued the impact that this had on the participants. Finally, the study is limited in community participation and mobility for young adults and did not inquire on stress, anxiety, or other impacts that the COVID-19 shutdowns and quarantines may have on the individual and or their transport providers (Wang, 2020).

\section{Conclusion}

Results of the current study identified that community mobility and participation decreased for all participants in both essential and non-essential activities. Additionally, 


\section{Participant 5}

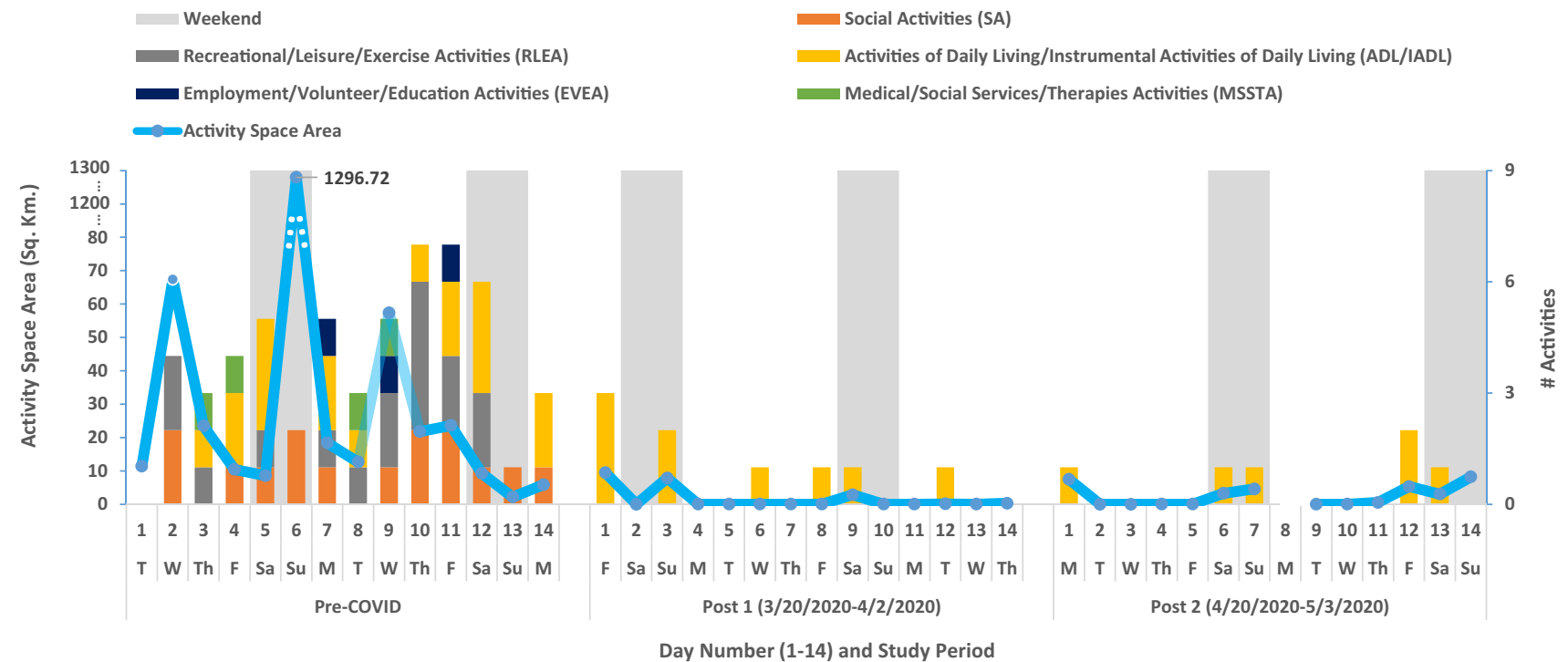

Fig. 8 Daily activity space area, destinations and activities for participant 5

\section{Participant 6}

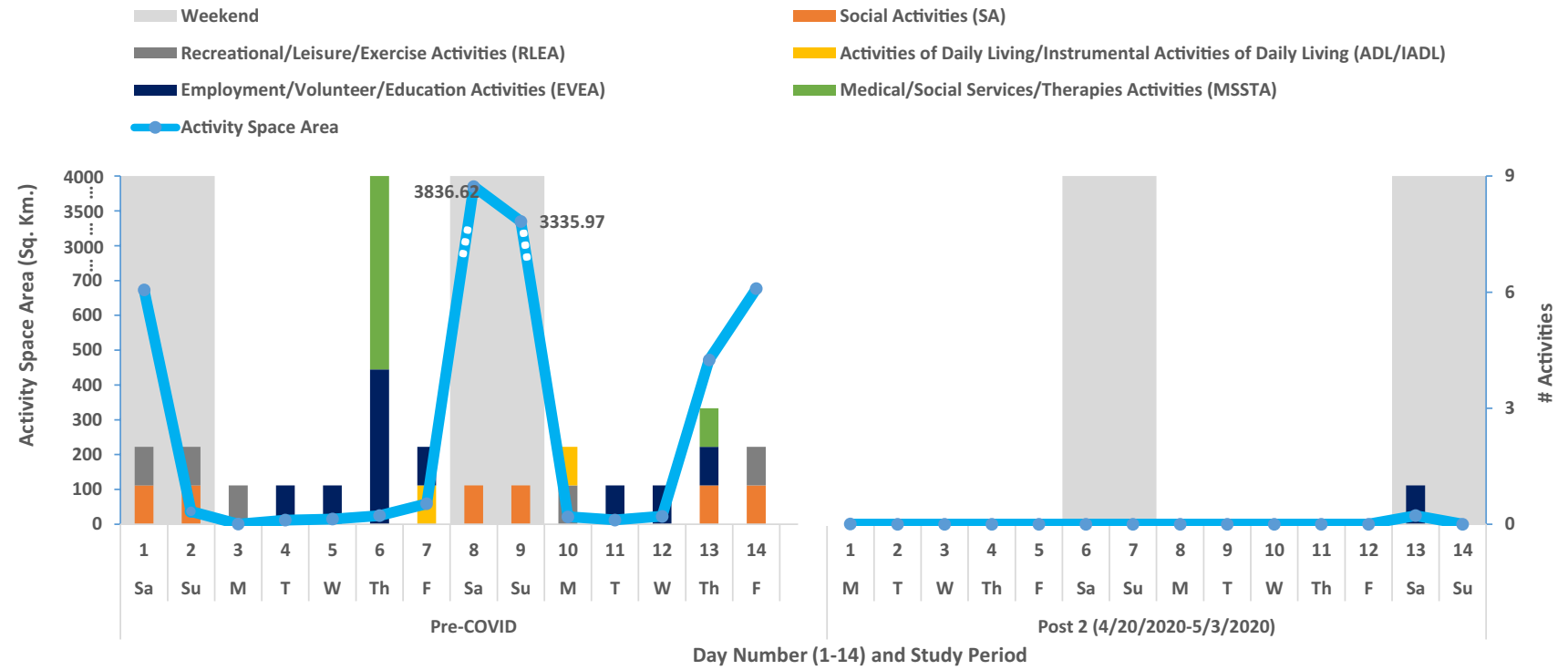

Fig. 9 Daily activity space area, destinations and activities for participant 6

the number of trips for participants decreased substantially in the after COVID-19 periods, as did the variability in modes of transit which were limited to walking and driving after the start of the pandemic. The expected reduction in community mobility and participation is consistent with the literature in the general population, although results illustrated the lack of variability in transportation modes for individuals with ASD after the start of the pandemic. None of the participants reported any type of travel provided by a social or human services agency to ensure essential needs were being met during this time period. This study was limited by its focus on a small group of young adults who were able to travel by at least one of mode of transportation in the community with only minimal supports. Additionally, the study did not examine other methods of community participation such as the use of remote technology that occurred in settings (e.g., home) not located in the physical community. 
Acknowledgments The contents of this article were developed under a grant from the National Institute on Disability, Independent Living, and Rehabilitation Research (NIDILRR Grant Number 90IFRE001301-00). NIDILRR is a Center within the Administration for Community Living (ACL), Department of Health and Human Services (HHS). The contents of this article do not necessarily represent the policy of NIDILRR, ACL, or HHS, and you should not assume endorsement by the Federal Government.

Author contributions All authors were involved in the conceptualization of the study. BP, EB, CF and MS formulated the design and primary research questions for the study. Material preparation, data collection, data management and analysis were initially performed by $\mathrm{EB}, \mathrm{LS}$, and APD and then reviewed and interpreted by all authors. BP, $\mathrm{EB}, \mathrm{CF}$ and TH drafted the initial manuscript and all authors provided feedback for revisions throughout the development and drafting of the various versions of the manuscript. All authors read and approved the final manuscript.

\section{References}

American Occupational Therapy Association. (2008). Occupational therapy practice framework: Domain \& process, 2 nd edition. American Journal of Occupational Therapy, 62(6), 625-683. https://doi.org/10.5014/ajot.62.6.625

Birant, D., \& Kut, A. (2007). ST-DBSCAN: An algorithm for clustering spatial-temporal data. Data \& Knowledge Engineering, 60(1), 208-221. https://doi.org/10.1016/j.datak.2006.01.013

Boissy, P., Blamoutier, M., Brière, S., \& Duval, C. (2018). Quantification of free-living community mobility in healthy older adults using wearable sensors. Frontiers in Public Health, 6, 216. https:// doi.org/10.3389/fpubh.2018.00216

Borgonovi, F., \& Andrieu, E. (2020). Bowling together by bowling alone: Social capital and COVID-19. Social Science \& Medicine, 265, 113501. https://doi.org/10.1016/j.socscimed.2020.113501

Brusilovskiy, E., Klein, L. A., \& Salzer, M. S. (2016). Using global positioning systems to study health-related mobility and participation. Social Science \& Medicine, 161, 134-142. https://doi.org/ 10.1016/j.socscimed.2016.06.001

Brusilovskiy, E., Klein, L. A., Townley, G., Snethen, G., McCormick, B., Hiremath, S. V., \& Salzer, M. S. (2020). Examining the relationship between community mobility and participation using GPS and self-report data. Social Science \& Medicine, 265, 113539. https://doi.org/10.1016/j.socscimed.2020.113539

Centers for Disease Control and Prevention. (2020, April 7). Coronavirus disease 2019 (COVID-19): People with disabilities. https:// www.cdc.gov/coronavirus/2019-ncov/need-extra-precautions/ people-with-disabilities.html

Centers for Disease Control and Prevention. (2020, December 29). COVID-19 and your health: People with certain medical conditions. Centers for Disease Control and Prevention.

Chan, D. V., Thorpe, D. E., Trost, S. G., Boyd, R. N., Faldowski, R. A., Barber, L., Levin, I., Carroll, A., \& Bagatell, N. (2020). Novel approaches to measuring community integration in adults with cerebral palsy. Disability and Rehabilitation, 42(18), 2653-2664. https://doi.org/10.1080/09638288.2019.1577500

Cochran, A. L. (2020). Impacts of COVID-19 on access to transportation for people with disabilities. Transportation Research Interdisciplinary Perspectives, 8, 100263. https://doi.org/10.1016/j. trip.2020.100263

Constantino, J. N., Sahin, M., Piven, J., Rodgers, R., \& Tschida, J. (2020). The impact of COVID-19 on individuals with intellectual and developmental disabilities: Clinical and scientific priorities.
American Journal of Psychiatry, 177(11), 1091-1093. https://doi. org/10.1176/appi.ajp.2020.20060780

Courtenay, K., \& Perera, B. (2020). COVID-19 and people with intellectual disability: Impacts of a pandemic. Irish Journal of Psychological Medicine, 37(3), 231-236. https://doi.org/10.1017/ ipm.2020.45

Davies, D. K., Stock, S. E., Holloway, S., \& Wehmeyer, M. L. (2010). Evaluating a GPS-based transportation device to support independent bus travel by people with intellectual disability. Intellectual and Developmental Disabilities, 48(6), 454-463. https:// doi.org/10.1352/1934-9556-48.6.454

Emerson, E., \& Hatton, C. (2008). Socioeconomic disadvantage, social participation and networks and the self-rated health of English men and women with mild and moderate intellectual disabilities: Cross sectional survey. The European Journal of Public Health, 18(1), 31-37. https://doi.org/10.1093/eurpub/ckm041

Fazana, F., Alsadoon, A., Prasad, P. W. C., Costadopoulos, N., Elchouemi, A., \& Sreedharan, S. (2017). Integration of assistive and wearable technology to improve communication, social interaction and health monitoring for children with autism spectrum disorder (ASD). 2017 IEEE Region 10 Symposium (TENSYMP). https://doi.org/10.1109/TENCONSpring.2017.8070018.

Federal Emergency Management Agency. (2020). COVID-19 best practice information: Public transportation distancing. https:// www.fema.gov/sites/default/files/2020-07/fema_covid_bp_publictransportation-social-distancing.pdf

Feeley, C., Deka, D., Lubin, A., \& McGackin, M. (2015). Detour to the right place: A study with recommendations for addressing the transportation needs and barriers of adults on the Autism Spectrum in New Jersey. Rutgers The State University of New Jersey.

Friedman, C., \& Rizzolo, M. C. (2016). The state of transportation for people with intellectual and developmental disabilities in Medicaid home and community-based services 1915(c) Waivers. Journal of Disability Policy Studies, 27(3), 168-177. https://doi.org/ 10.1177/1044207316644413

Galea, S., Merchant, R. M., \& Lurie, N. (2020). The mental health consequences of COVID-19 and physical distancing: The need for prevention and early intervention. JAMA Internal Medicine, 180(6), 817. https://doi.org/10.1001/jamainternmed.2020.1562

Groover, H. (2020, April 22). Metro places passenger limits on buses to strengthen social distancing amid coronavirus outbreak. The Seattle Times. https://www.seattletimes.com/seattle-news/trans portation/metro-places-passenger-limits-on-buses-to-strengthensocial-distancing-amid-coronavirus-outbreak/

Guse, C. (2020, April 12). NJ Transit riders required to wear masks during coronavirus pandemic, MTA still 'recommending' them. New York Daily News. https://www.nydailynews.com/coronavirus/ ny-coronavirus-new-jersey-transit-masks-mta-20200412-htxwy hrd4fe5ndycymg44pbsti-story.html

Haveman, M., Tillmann, V., Stöppler, R., Kvas, Š., \& Monninger, D. (2013). Mobility and public transport use abilities of children and young adults with intellectual disabilities: Results from the 3-year Nordhorn Public Transportation Intervention Study. Journal of Policy and Practice in Intellectual Disabilities, 10, 289-299.

Hawkins, A. (2020, March 13). Coronavirus is taking a big bite out of public transportation ridership in the US. The Verge. https:// www.theverge.com/2020/3/13/21179032/public-transportationcoronavirus-covid19-ridership-nyc-sf-la-dc

Jeste, S., Hyde, C., Distefano, C., Halladay, A., Ray, S., Porath, M., Wilson, R. B., \& Thurm, A. (2020). Changes in access to educational and healthcare services for individuals with intellectual and developmental disabilities during COVID-19 restrictions. Journal of Intellectual Disability Research, 64(11), 825-833. https://doi. org/10.1111/jir.12776

Jones, K. B., Cottle, K., Bakian, A., Farley, M., Bilder, D., Coon, H., \& McMahon, W. M. (2016). A description of medical conditions 
in adults with autism spectrum disorder: A follow-up of the 1980s Utah/UCLA Autism Epidemiologic Study. Autism, 20(5), 551561. https://doi.org/10.1177/1362361315594798

Kishore, N., Kiang, M. V., Eng ø-Monsen, K., Vembar, N., Schroeder, A., Balsari, S., \& Buckee, C. O. (2020). Measuring mobility to monitor travel and physical distancing interventions: A common framework for mobile phone data analysis. The Lancet Digital Health, 2(11), e622-e628. https://doi.org/10.1016/S25897500(20)30193-X

Kohane, I. S., McMurry, A., Weber, G., MacFadden, D., Rappaport, L., Kunkel, L., Bickel, J., Wattanasin, N., Spence, S., Murphy, S., \& Churchill, S. (2012). The co-morbidity burden of children and young adults with autism spectrum disorders. PLOS ONE, 7(4), e33224. https://doi.org/10.1371/journal.pone.0033224

Kraemer, M. U. G., Yang, C.-H., Gutierrez, B., Wu, C.-H., Klein, B., Pigott, D. M., Open COVID-19 Data Working Group, du Plessis, L., Faria, N. R., Li, R., Hanage, W. P., Brownstein, J. S., Layan, M., Vespignani, A., Tian, H., Dye, C., Pybus, O. G., \& Scarpino, S. V. (2020). The effect of human mobility and control measures on the COVID-19 epidemic in China. Science, 368(6490), 493-497. https://doi.org/10.1126/science.abb4218

Lasry, A., Kidder, D., Hast, M., Poovey, J., Sunshine, G., Winglee, K., Zviedrite, N., Ahmed, F., Ethier, K. A., CDC Public Health Law Program, New York City Department of Health and Mental Hygiene, Louisiana Department of Health, Public Health - Seattle \& King County, San Francisco COVID-19 Response Team, Alameda County Public Health Department, San Mateo County Health Department, \& Marin County Division of Public Health. (2020). Timing of Community Mitigation and Changes in Reported COVID-19 and Community Mobility-Four U.S. Metropolitan Areas, February 26-April 1, 2020. MMWR. Morbidity and Mortality Weekly Report, 69(15), 451-457. https:// doi.org/10.15585/mmwr.mm6915e2

Lee, M., Zhao, J., Sun, Q., Pan, Y., Zhou, W., Xiong, C., \& Zhang, L. (2020). Human mobility trends during the early stage of the COVID-19 pandemic in the United States. PLOS ONE, 15(11), e0241468. https://doi.org/10.1371/journal.pone.0241468

Liptak, G. S., Kennedy, J. A., \& Dosa, N. P. (2011). Social participation in a nationally representative sample of older youth and young adults with autism. Journal of Developmental \& Behavioral Pediatrics, 32(4), 277-283. https://doi.org/10.1097/DBP. 0b013e31820b49fc

Little, L., \& Irvin, D. (2018). Community participation and language opportunities for children and without autism spectrum disorder. American Journal of Occupational Therapy, 72(4_Supplement_1), 7211500001p1

Little, L. M., Rojas, J. P., Bard, A., Luo, Y., Irvin, D., \& Rous, B. (2019). Automated measures to understand communication opportunities for young children with autism in the community: A pilot study. OTJR: Occupation, Participation and Health, 39(2), 124-130

Manning, J., Billian, J., Matson, J., Allen, C., \& Soares, N. (2020). Perceptions of families of individuals with autism spectrum disorder during the COVID-19 crisis. Journal of Autism and Developmental Disorders. https://doi.org/10.1007/ s10803-020-04760-5

McCormick, B., Brusilovskiy, E., Snethen, G., Townley, G., \& Salzer, M. (2021). Getting out of the house: the relationship of venturing into the community and neurocognition among adults with serious mental illnesses. Psychiatric Rehabilitation Journal. https://doi. org/10.1037/prj0000483

Metropolitan Transportation Authority. (2021, January 8). MTA service during the coronavirus pandemic. MTA. https://new.mta.info/ coronavirus

Myers, E., Davis, B. E., Stobbe, G., \& Bjornson, K. (2015). Community and social participation among individuals with autism spectrum disorder transitioning to adulthood. Journal of Autism and Developmental Disorders, 45(8), 2373-2381. https://doi.org/ 10.1007/s10803-015-2403-z

Newman, L., Wagner, M., Knokey, A., Marder, C., Nagle, K., Shaver, D., \& Wei, X. (2011). The post-high school outcomes of young adults with disabilities up to 8 years after high school: A report from the National Longitudinal Transition Study-2 (NLTS2). Institute of Education Sciences National Center for Special Education Research.

Office of the Governor. (2020, March 13). Governor Wolf announces closure of Pennsylvania Schools [Press Release]. https://www. governor.pa.gov/newsroom/governor-wolf-announces-closureof-pennsylvania-schools/

Office of the Governor. (2020, March 23). Gov. Wolf puts statewide COVID-19 mitigation efforts in effect, stresses need for every pennsylvanian to take action to stop the spread [Press Release]. https://www.governor.pa.gov/newsroom/governor-wolf-andhealth-secretary-issue-stay-at-home-orders-to-7-counties-to-mitig ate-spread-of-covid-19/

Patel, J., Badiani, A., Nielsen, F., Assi, S., Unadkat, V., Patel, B., Courtney, C., \& Hallas, L. (2020). COVID-19 and autism: Uncertainty, distress and feeling forgotten. Public Health in Practice, 1, 100034. https://doi.org/10.1016/j.puhip.2020.100034

Pellicano, E., \& Stears, M. (2020). The hidden inequalities of COVID19. Autism, 24(6), 1309-1310. https://doi.org/10.1177/13623 61320927590

Pfeiffer, B., Classen, S., Persch, A., Kramer, J., Bevans, K., Raphael, A., \& Fleming, C. (2018, April). Transportation and community participation for individuals with developmental disabilities. Paper Presented at American Occupational Therapy Association.

Pfeiffer, B., Sell, A., \& Bevans, K. B. (2020). Initial evaluation of a public transportation training program for individuals with intellectual and developmental disabilities: Short report. Journal of Transport \& Health, 16, 100813. https://doi.org/10.1016/j.jth. 2019.100813

Price, R., Marsh, A. J., \& Fisher, M. H. (2018). Teaching young adults with intellectual and developmental disabilities communitybased navigation skills to take public transportation. Behavior Analysis in Practice, 11(1), 46-50. https://doi.org/10.1007/ s40617-017-0202-z

Serafini, G., Parmigiani, B., Amerio, A., Aguglia, A., Sher, L., \& Amore, M. (2020). The psychological impact of COVID-19 on the mental health in the general population. QJM: An International Journal of Medicine, 113(8), 531-537. https://doi.org/10. 1093/qjmed/hcaa201

Simpson, K., Adams, D., Bruck, S., \& Keen, D. (2019). Investigating the participation of children on the autism spectrum across home, school, and community: A longitudinal study. Child: Care, Health and Development, 45(5), 681-687. https://doi.org/10.1111/cch. 12679

Solomon, M. Z., Wynia, M. K., \& Gostin, L. O. (2020). Covid-19 crisis triage-optimizing health outcomes and disability rights. New England Journal of Medicine, 383(5), e27. https://doi.org/ 10.1056/NEJMp2008300

Southeastern Pennsylvania Transportation Authority. (n.d.). COVID19 Information. Retrieved January 22, 2021, from http://septa. org/covid-19/

Thompson, J. R., \& Nygren, M. A. (2020). COVID-19 and the field of intellectual and developmental disabilities: Where have we been? Where are we? Where do we go? Intellectual and Developmental Disabilities, 58(4), 257-261. https://doi.org/10.1352/1934-955658.4.257

Trump, D. J. (2020, March 13). Proclamation on declaring a national emergency concerning the novel coronavirus disease (COVID-19) outbreak. The White House. https://trumpwhitehouse.archives. 
gov/presidential-actions/proclamation-declaring-national-emerg ency-concerning-novel-coronavirus-disease-covid-19-outbreak/

Wang, C. (2020). The impact of COVID-19 on autism research: Reflections from China. Autism Research, 13(7), 1028-1028. https://doi. org/10.1002/aur.2344

Wolf, T. (2020a). Order of the Governor of the Commonwealth of Pennsylvania regarding the closure of all businesses that are not life sustaining. Office of the Governor. https://www.scribd.com/ document/452416027/20200319-TWW-COVID-19-BusinessClosure-Order

Wolf, T. (2020b). Order of the Governor of the Commonwealth of Pennsylvania for individuals to stay at home. Office of the Governor. https://www.governor.pa.gov/wp-content/uploads/2020/04/ 20200401-GOV-Statewide-Stay-at-Home-Order.pdf

Zhou, C., Frankowski, D., Ludford, P., Shekhar, S., \& Terveen, L. (2004). Discovering personal gazetteers: An interactive clustering approach. Proceedings of the 12th Annual ACM International Workshop on Geographic Information Systems - GIS '04, 266. https://doi.org/10.1145/1032222.1032261

Zhou, C., Ludford, P., Frankowski, D., \& Terveen, L. (2005). How do people's concepts of place relate to physical locations? In M. F. Costabile \& F. Paternò (Eds.), Human-computer interactionINTERACT 2005 (Vol. 3585, pp. 886-898). Springer. https://doi. org/10.1007/11555261_70

Publisher's Note Springer Nature remains neutral with regard to jurisdictional claims in published maps and institutional affiliations. 